\title{
Review Article \\ The Role of miRNAs in the Regulation of Pancreatic Cancer Stem Cells
}

\author{
Sabrina Bimonte, ${ }^{1}$ Antonio Barbieri, ${ }^{2}$ Maddalena Leongito, ${ }^{1}$ Giuseppe Palma, ${ }^{2}$ \\ Vitale del Vecchio, ${ }^{2}$ Michela Falco, ${ }^{2}$ Raffaele Palaia, ${ }^{1}$ Vittorio Albino, ${ }^{1}$ Mauro Piccirillo, ${ }^{1}$ \\ Alfonso Amore, ${ }^{1}$ Antonella Petrillo, ${ }^{3}$ Vincenza Granata, ${ }^{3}$ and Francesco Izzo ${ }^{1}$ \\ ${ }^{1}$ Division of Abdominal Surgical Oncology, Hepatobiliary Unit, National Cancer Institute "G. Pascale Foundation", \\ IRCCS, 80131 Naples, Italy \\ ${ }^{2}$ Animal Facility Unit, National Cancer Institute “G. Pascale Foundation”, IRCCS, 80131 Naples, Italy \\ ${ }^{3}$ Division of Radiology, National Cancer Institute “G. Pascale Foundation”, IRCCS, 80131 Naples, Italy \\ Correspondence should be addressed to Sabrina Bimonte; s.bimonte@istitutotumori.na.it
}

Received 18 November 2015; Revised 24 December 2015; Accepted 27 January 2016

Academic Editor: $\mathrm{Hu} \mathrm{Li}$

Copyright (C) 2016 Sabrina Bimonte et al. This is an open access article distributed under the Creative Commons Attribution License, which permits unrestricted use, distribution, and reproduction in any medium, provided the original work is properly cited.

\begin{abstract}
Pancreatic ductal adenocarcinoma is currently one of the deadliest cancers with low overall survival rate. This disease leads to an aggressive local invasion and early metastases and is poorly responsive to treatment with chemotherapy or chemoradiotherapy. Several studies have shown that pancreatic cancer stem cells (PCSCs) play different roles in the regulation of drug resistance and recurrence in pancreatic cancer. MicroRNA (miRNA), a class of newly emerging small noncoding RNAs, is involved in the modulation of several biological activities ranging from invasion to metastases development, as well as drug resistance of pancreatic cancer. In this review, we synthesize the latest findings on the role of miRNAs in regulating different biological properties of pancreatic cancer stem cells.
\end{abstract}

\section{Introduction}

Pancreatic ductal adenocarcinoma (PDAC) is currently the fourth leading cause of cancer death in the United States and the seventh worldwide, with low overall survival rate $[1,2]$. Surgical resection remains the only curative therapeutic treatment for this aggressive disease, although the minority of the patients can undergo resection as consequence of tardive diagnosis $[3,4]$. PDAC leads to an aggressive local invasion and early metastases, and it is noted that this disease is poorly responsive to treatment with chemotherapy or radiation therapy [5-7]. To date, gemcitabine is the best chemotherapeutic agent used for pancreatic cancer treatment, although patients showed drug resistance over the time [8-11]. In order to improve PDAC prognosis and to bypass the problem of pancreatic tumor chemoresistance, many alternative treatments have been proposed [12]. Unfortunately, the results are not very encouraging, since the overall survival of patients was not significantly improved. Emerging studies showed that cancer stem cells (CSCs) regulate several mechanisms underlying drug resistance, carcinogenesis, and metastases development in various types of cancer including pancreatic cancer, highlighting the possibility that these cells could represent valid candidates to ameliorate pancreatic cancer prognosis [13, 14].

CSCs were identified for the first time in acute myeloid leukemia $[15,16]$ and then in the solid tumors, including pancreatic cancer [17-19]. These cells are able to differentiate into several cancer cell types [20] and are involved in the initiation, the propagation, and the therapeutic resistance of various types of human cancer [21-25]. Pancreatic cancer stem cells (PCSCs) show the same properties of normal stem cells and can regulate pancreatic tumorigenesis. It has also been demonstrated that these cells can play several roles in the regulation of chemoresistance in pancreatic cancer $[22,26,27]$, although the underlying mechanisms are not 
completely elucidated. Recent studies dissected the role of microRNAs (miRNAs) and PCSCs on the modulation of pancreatic cancer etiology and progression, shedding light on their importance as potential therapeutic targets for pancreatic cancer [17, 28-31]. In this review, we synthesize the latest findings on the role of miRNAs in regulating key biological properties of pancreatic cancer stem cells.

\section{Characteristics of Pancreatic Cancer Stem Cells (PCSCs)}

PCSCs, also named tumor-initiating pancreatic cancer stem cells, were described by Li et al. [22], through the generation of a mouse model of human pancreatic adenocarcinoma. The authors isolated these subsets of cells as $\mathrm{CD} 24^{+} \mathrm{CD} 44^{+} \mathrm{ESA}^{+}$ (epithelial specific antigen), which, despite accounting for less than $1 \%$ of all pancreatic cancer cells, showed a highly tumorigenic potential respect to noncarcinogenic cancer cells. Later on, many studies based on several xenograft models identified other markers for pancreatic cancer stem cells such as CD133, c-Met, ALDH1 (aldehyde dehydrogenease-1), Lgr5 (leucinerich repeat-containing G-protein coupled receptor 5), and DclK1 (doublecortin-like kinase 1) (Figure 1) [17, 47-54], although further studies will be necessary to better define the cell surface markers of PCSCs.

\section{Signaling Pathway Involved in the Regulation of Pancreatic Cancer Stem Cells (PCSCs)}

The properties of PCSCs have been investigated by dissecting the underlying signaling pathways and regulatory genes such as Wnt $/ \beta$ catenin, Notch, c-myc, Sonic Hedgehog, and Bmi-1 [32, 47, 55, 56] (Table 1). The Hedgehog signaling (Hh) pathway plays a key regulator role in the embryonic development and patterning $[33,57]$ and it is activated by a complex mechanism of interaction between three Hedgehog (Hh) ligand proteins (Sonic, Indian, and Desert $\mathrm{Hh}$ ) and cell surface receptors patched (Ptch1 and Ptch2) [13]. It is of note that Hh signaling is necessary for the PCSCs renewal and the maintenance of stemness [58-63]. Notch signaling controls pancreatic self-differentiation by acting on the selfrenewal process [64]. Moreover, it has been demonstrated that Notch-1 is involved in the epithelial-mesenchymal transition (EMT) of Aspc-1 pancreatic cancer cell line [65] and in the maintenance of the cancer stem cell population [34]. These studies suggest that Notch signaling is essential for the pancreatic CSC formation. Another signaling involved in the organogenesis of the pancreas is the Wnt- $\beta$-catenin signaling pathway. It has been demonstrated that Wnt signaling is associated with EMT process in colorectal cancer [66]. Other studies proved that different pathways are involved in the maintenance of pancreatic CSCs such as NF- $\kappa \mathrm{B}$ [67] and mTOR pathway [68].

Altogether, these results suggest that different signaling pathways are involved in the self-renewal and the maintenance of pancreatic cancer stem cells.

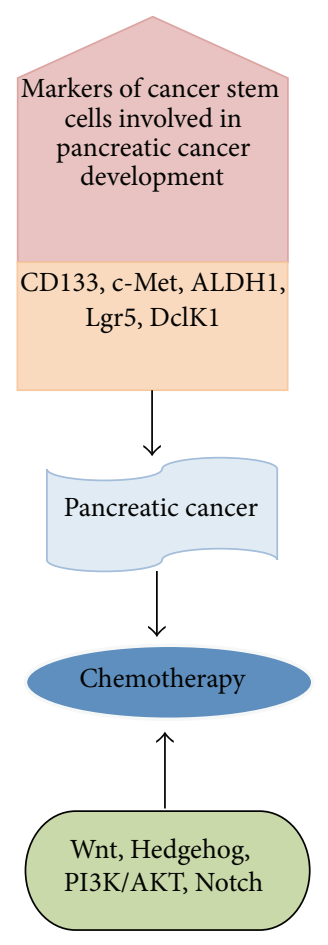

FIGURE 1: The role of cancer stem cells markers during pancreatic cancer development. The cartoon recapitulates the role of cancer stem cells markers during pancreatic cancer development and the signaling pathways involved.

\section{The Biogenesis of MicroRNAs (miRNAs)}

MicroRNAs (miRNAs) are small noncoding RNAs involved in the regulation of gene expression at posttranscriptional level by binding to the $3^{\prime}$-untranslated regions ( $3^{\prime}$ UTRs) or the open reading frames of target genes. This leads to the repression of mRNA translation or to the degradation of target mRNAs [69]. miRNAs are single-stranded, 18-25 nucleotides long. In animals, they are transcribed as long primary transcripts (pri-miRNA) by RNA polymerase II, which are processed in the nucleus by RNase III Drosha into 70-100-nucleotide-long precursor named hairpin miRNAs (pre-miRNAs) [70]. Then, pre-miRNAs are exported to the cytoplasm by Exportin-5 [71-73] and further cleaved in a complex composed of RNase III enzyme, Dicer, and the transactivating response RNA-binding protein (TRBP) into complex named miRNA:miRNA* [74-77]. The complementary star strand $\left(\right.$ miRNA $^{*}$ ) is usually degraded, even if it has been suggested that when it is not degraded, it may have some relevant biological functions [78, 79]. The other strand is chosen as a guide strand that recognizes target mRNAs on the basis of complementarity of sequence. This mature miRNA is loaded into an Argonaute protein within the RNA-induced silencing complex (RISC), which then regulates targets repression by promoting destabilization or inhibiting translation of target mRNA [80-83]. Experimental data showed that miRNAs bind to the open reading frame or to the $5^{\prime}$ UTR $[84,85]$. The biogenesis of miRNA is showed in Figure 2 . 
TABLE 1: Self-renewal pathways in PCSCs.

\begin{tabular}{|c|c|c|c|}
\hline Signaling pathways & Effects on tumorigenesis and drug resistance & Targets & Reference \\
\hline Hedgehog & Proliferation & $\mathrm{ALDH}^{+} \mathrm{CD}_{4} 4^{+} \mathrm{CD} 24^{+} \mathrm{ESA}^{+}$ & [32-34] \\
\hline ALK4 & Invasion and metastasis & $\mathrm{CD} 133^{+}$ & {$[35]$} \\
\hline Notch & Proliferation & $\mathrm{ALDH}^{+}$ & {$[34]$} \\
\hline c-Met & Drug resistance & 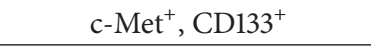 & {$[36]$} \\
\hline
\end{tabular}

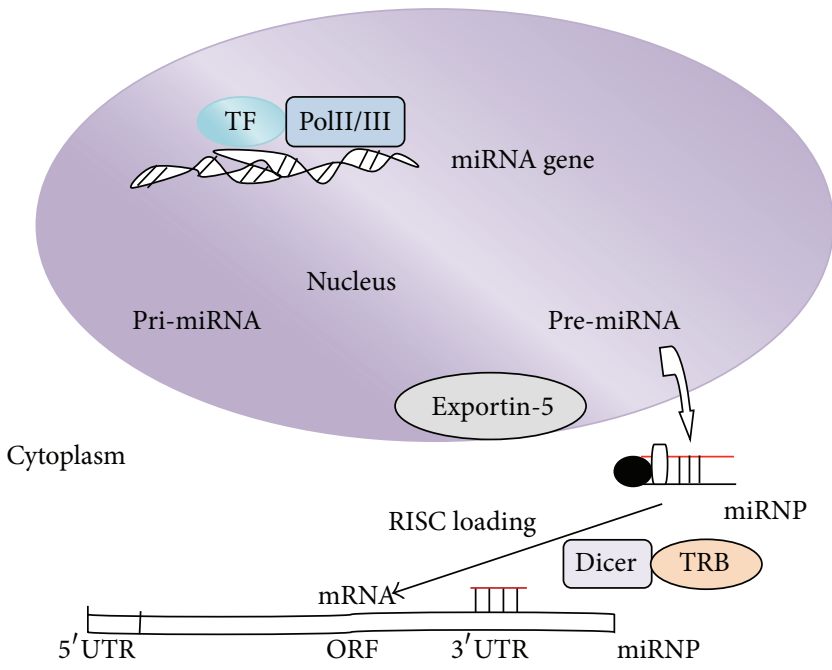

FIgure 2: The miRNAs biogenesis.

RNA polymerase II transcribes miRNA genes together with specific transcription factors (TF), as long primary transcripts (pri-miRNA). These transcripts are processed in the nucleus by the RNA polymerase III enzyme Drosha, in complex with DGCR8, into pre-miRNAs. These transcripts are exported into the cytoplasm by Exportin-5. Pre-miRNAs are processed by the RNase III enzyme Dicer, in complex with TRBP, into a duplex of a guide strand (miRNA) and passenger star strand (miRNA*). The guide stand miRNA is loaded into the RISC and is able to recognize target mRNAs on the basis of sequence complementarity. The RISC regulates target repression.

\section{The Regulatory Functions of miRNAs on PCSCs Properties}

Many studies demonstrated that miRNAs play critical roles in the regulation of CSCs in different types of malignant tumors including pancreatic cancer and have been considered potential targets for cancer therapy, since they are involved in the initiation, the propagation, and the regulation of EMT of cancer stem cells [39, 43, 86-92]. Several miRNAs show different expression profiles in various types of cancer, including pancreatic cancer $[93,94]$. Moreover, there is a difference between the miRNA complement of cancer cells and those of nontumor cells. miRNAs can be classified in two different groups based on their role on the progression of human cancer and their expression profile: (1) the oncogenic miRNAs (miR-21, miR-155, miR-17-5p, etc.) that are upregulated in tumor cells $[65,95]$; (2) the tumor suppressor miRNAs (miR-34, miR-15a, miR-16-1, let-7, etc.), which are downregulated in pancreatic cancer $[43,96]$.

Regarding the role of oncogenic miRNAs on PCSCs properties, interesting studies provided evidence that miR-21 modulates the proliferation and the chemoresistance of pancreatic cancer cells [37, 38]. In addition, Giovannetti et al. [97] showed that there is a correlation between miR-21 expression and the clinical outcome of patients with pancreatic cancer through involvement of PI3K/AKT pathway.

On the other hand, other studies showed that upregulated expression of miR-34, which is classified as tumor suppressor miRNA and is regulated by p53, leads to the inhibition of human pancreatic cancer tumor-initiating cells, indicating that miR-34 is involved in the self-renewal process of PCSCs $[43,44]$.

Hasegawa et al. [46] provided evidence that the overexpression of miRNA-1246 is associated with CCNG2-mediated chemoresistance and stemness in pancreatic cancer.

Studies performed on the expression of various types of miR-200, classified with tumor suppressor miRNAs, demonstrated that these miRNAs can regulate cell maintenance and EMT (by reducing levels of EMT markers) of PCSCs [40].

It has been reported that DCLK1 (a putative marker for pancreatic and intestinal cancer stem cells) regulates EMT in human pancreatic cancer cells through a mechanism dependent on miR-200a [41]. In this paper, the authors demonstrated that DCAMKL-1 expression was upregulated in human pancreatic adenocarcinoma tissue and in a KRAS transgenic mouse model of pancreatic cancer.

Experimental research proved that Zinc finger E-box binding homeobox 1 (ZEB1) is a crucial EMT promoter and inhibits expression of the microRNA-200 (miR-200) family and miR-203, resulting in the maintenance of stemness and EMT activation in colorectal and pancreatic cancer [42].

Pancreatic cancer cell growth can be inhibited also by a complex mechanism of regulation mediated by two tumor suppressor miRNAs, miR-143 and miR-145. Pramanik et al. [45] demonstrated that restoration of miR-143/145 levels, using a systemic nanovector, is able to inhibit pancreatic cancer cell growth in mice. This process seems to be mediated by a negative feedback loop in KRAS/RREB1-miR-143/145. The regulatory functions of miRNAs on the biological properties of PCSs are summarized in Table 2.

Deregulation of miRNAs is also associated with the renewal and the differentiation of stem cells into cancer stem cells, as reported by Garg et al. [98, 99]. Moreover, some important regulators of the stem cell pluripotency (such as Sox 9 and Nanog) and miRNAs targets have been described by Ahmed et al. [100]. 
TABLE 2: The regulatory functions of miRNAs on PCSCs properties.

\begin{tabular}{lcccc}
\hline Upregulation of onco-miRNAs & $\begin{array}{c}\text { Downregulation of tumor suppressor } \\
\text { miRNAs }\end{array}$ & Potential targets & Biological PCSCs behavior & Reference \\
\hline miR-21 & miR-200a/c & PI3K/AKT & Proliferation and chemoresistance & {$[37-39]$} \\
& miR-34 & $n$-cadherin, ZEB 1 & EMT, stemness maintenance & [40-42] \\
& miR-143/miR-145 & BCL2 & Self-renewal & [43, 44] \\
& miR-1246 & Kras & Cancer cell growth \\
& & CCNG2 & Chemoresistance and stemness & {$[46]$} \\
\hline
\end{tabular}

An experimental approach based on microarray analysis demonstrated a linkage between clusters of miRNAs and clusters of stem cell-associated miRNAs in cancer stem cells [101]. Bao et al. [102] demonstrated that metformin inhibits cell proliferation, migration, and invasion of drug resistant pancreatic cancer cells by attenuating CSC function. This process is mediated by deregulation of miRNAs (let-7a, let-7b, miR-26a, miR-101, miR-200b, and miR-200c) in pancreatic cancer cells.

Altogether, these data suggest that a better comprehension of the regulatory feedback loop between miRNAs and CSC in pancreatic cancer could lead to the development of novel strategies in the treatment of pancreatic cancer patients by CSCs elimination.

\section{Conclusions}

Emerging data summarized in this review showed that miRNAs can function as oncogenes or tumor suppressors, playing important roles in the modulation of several biological activities of PCSCs. Despite these encouraging results, more studies on the function of miRNAs in PCSC biology will be needed in the future in order to improve pancreatic cancer treatments by using miRNAs, as innovative approach.

\section{Conflict of Interests}

The authors declare that there is no conflict of interests regarding the publication of this paper.

\section{Authors' Contribution}

Sabrina Bimonte and Antonio Barbieri contributed equally to this paper.

\section{Acknowledgments}

The authors thank Massimiliano Spinelli, for kindly helping in providing informatics assistance. This work was supported by current research programs of National Institute of Tumors, IRCCS “Foundation G. Pascale," Naples (Italy).

\section{References}

[1] R. Siegel, J. Ma, Z. Zou, and A. Jemal, "Cancer statistics, 2014," CA Cancer Journal for Clinicians, vol. 64, no. 1, pp. 9-29, 2014.
[2] H. Oettle, "Progress in the knowledge and treatment of advanced pancreatic cancer: from benchside to bedside," Cancer Treatment Reviews, vol. 40, no. 9, pp. 1039-1047, 2014.

[3] J. Ferlay, D. M. Parkin, and E. Steliarova-Foucher, "Estimates of cancer incidence and mortality in Europe in 2008," European Journal of Cancer, vol. 46, no. 4, pp. 765-781, 2010.

[4] G. J. Krejs, "Pancreatic cancer: epidemiology and risk factors," Digestive Diseases, vol. 28, no. 2, pp. 355-358, 2010.

[5] T. Conroy, F. Desseigne, M. Ychou et al., "FOLFIRINOX versus gemcitabine for metastatic pancreatic cancer," The New England Journal of Medicine, vol. 364, no. 19, pp. 1817-1825, 2011.

[6] D. Cunningham, I. Chau, D. D. Stocken et al., "Phase III randomized comparison of gemcitabine versus gemcitabine plus capecitabine in patients with advanced pancreatic cancer," Journal of Clinical Oncology, vol. 27, no. 33, pp. 5513-5518, 2009.

[7] H. A. Burris III, M. J. Moore, J. Andersen et al., "Improvements in survival and clinical benefit with gemcitabine as firstline therapy for patients with advanced pancreas cancer: a randomized trial," Journal of Clinical Oncology, vol. 15, no. 6, pp. 2403-2413, 1997.

[8] H. Oettle and T. Lehmann, "Gemcitabine-resistant pancreatic cancer: a second-line option," The Lancet, 2015.

[9] S.-N. Tang, J. Fu, S. Shankar, and R. K. Srivastava, "EGCG enhances the therapeutic potential of gemcitabine and CP690550 by inhibiting STAT3 signaling pathway in human pancreatic cancer," PLoS ONE, vol. 7, no. 2, Article ID e31067, 2012.

[10] E. Giovannetti, L. G. Leon, S. Bertini et al., "Study of apoptosis induction and deoxycytidine kinase/cytidine deaminase modulation in the synergistic interaction of a novel ceramide analog and gemcitabine in pancreatic cancer cells," Nucleosides, Nucleotides \& Nucleic Acids, vol. 29, no. 4-6, pp. 419-426, 2010.

[11] L. R. Jaidev, U. M. Krishnan, and S. Sethuraman, "Gemcitabine loaded biodegradable PLGA nanospheres for in vitro pancreatic cancer therapy," Materials Science and Engineering C: Materials for Biological Applications, vol. 47, pp. 40-47, 2015.

[12] E. Leclerc and S. W. Vetter, "The role of S100 proteins and their receptor RAGE in pancreatic cancer," Biochimica et Biophysica Acta, vol. 1852, no. 12, pp. 2706-2711, 2015.

[13] Y. Y. Zhu and Z. Yuan, "Pancreatic cancer stem cells," American Journal of Cancer Research, vol. 5, no. 3, pp. 894-906, 2015.

[14] S. Tanaka, "Cancer stem cells as therapeutic targets of hepatobiliary-pancreatic cancers," Journal of Hepato-Biliary-Pancreatic Sciences, vol. 22, no. 7, pp. 531-537, 2015.

[15] D. Bonnet and J. E. Dick, "Human acute myeloid leukemia is organized as a hierarchy that originates from a primitive hematopoietic cell," Nature Medicine, vol. 3, no. 7, pp. 730-737, 1997. 
[16] T. Lapidot, C. Sirard, J. Vormoor et al., "A cell initiating human acute myeloid leukaemia after transplantation into SCID mice," Nature, vol. 367, no. 6464, pp. 645-648, 1994.

[17] P. C. Hermann, S. L. Huber, T. Herrler et al., "Distinct populations of cancer stem cells determine tumor growth and metastatic activity in human pancreatic cancer," Cell Stem Cell, vol. 1, no. 3, pp. 313-323, 2007.

[18] A. Van den Broeck, H. Vankelecom, W. Van Delm et al., "Human pancreatic cancer contains a side population expressing cancer stem cell-associated and prognostic genes," PLoS ONE, vol. 8, no. 9, Article ID e73968, 2013.

[19] J. L. Kopp and M. Sander, "New insights into the cell lineage of pancreatic ductal adenocarcinoma: evidence for tumor stem cells in premalignant lesions?" Gastroenterology, vol. 146, no. 1, pp. 24-26, 2014.

[20] M. F. Clarke, J. E. Dick, P. B. Dirks et al., "Cancer stem cellsperspectives on current status and future directions: AACR workshop on cancer stem cells," Cancer Research, vol. 66, no. 19, pp. 9339-9344, 2006.

[21] C. J. Lee, J. Dosch, and D. M. Simeone, "Pancreatic cancer stem cells,” Journal of Clinical Oncology, vol. 26, no. 17, pp. 2806-2812, 2008.

[22] C. Li, D. G. Heidt, P. Dalerba et al., "Identification of pancreatic cancer stem cells," Cancer Research, vol. 67, no. 3, pp. 1030-1037, 2007.

[23] J. E. Visvader and G. J. Lindeman, "Cancer stem cells: current status and evolving complexities," Cell Stem Cell, vol. 10, no. 6, pp. 717-728, 2012.

[24] E. Fessler, F. E. Dijkgraaf, F. De Sousa E Melo, and J. P. Medema, "Cancer stem cell dynamics in tumor progression and metastasis: is the microenvironment to blame?" Cancer Letters, vol. 341, no. 1, pp. 97-104, 2013.

[25] X. Wang, Y. Zhu, Y. Ma et al., "The role of cancer stem cells in cancer metastasis: new perspective and progress," Cancer Epidemiology, vol. 37, no. 1, pp. 60-63, 2013.

[26] J. A. Castellanos, N. B. Merchant, and N. S. Nagathihalli, "Emerging targets in pancreatic cancer: epithelial-mesenchymal transition and cancer stem cells," OncoTargets and Therapy, vol. 6, pp. 1261-1267, 2013.

[27] J. Xia, C. Chen, Z. Chen, L. Miele, F. H. Sarkar, and Z. Wang, "Targeting pancreatic cancer stem cells for cancer therapy," Biochimica et Biophysica Acta (BBA)-Reviews on Cancer, vol. 1826, no. 2, pp. 385-399, 2012.

[28] F. H. Sarkar, Y. Li, Z. Wang, D. Kong, and S. Ali, "Implication of microRNAs in drug resistance for designing novel cancer therapy," Drug Resistance Updates, vol. 13, no. 3, pp. 57-66, 2010.

[29] M. Danquah, S. Singh, S. W. Behrman, and R. I. Mahato, "Role of miRNA and cancer stem cells in chemoresistance and pancreatic cancer treatment," Expert Opinion on Drug Delivery, vol. 9, no. 12, pp. 1443-1447, 2012.

[30] B. E. Kadera, L. Li, P. A. Toste et al., "MicroRNA-21 in pancreatic ductal adenocarcinoma tumor-associated fibroblasts promotes metastasis," PLoS ONE, vol. 8, no. 8, Article ID e71978, 2013.

[31] L. Sun, C. Y. X. Chua, W. Tian, Z. Zhang, P. J. Chiao, and W. Zhang, "MicroRNA signaling pathway network in pancreatic ductal adenocarcinoma," Journal of Genetics and Genomics, vol. 42, no. 10, pp. 563-577, 2015.

[32] H. Onishi and M. Katano, "Hedgehog signaling pathway as a new therapeutic target in pancreatic cancer," World Journal of Gastroenterology, vol. 20, no. 9, pp. 2335-2342, 2014.
[33] J. Xie, C. M. Bartels, S. W. Barton, and D. Gu, "Targeting hedgehog signaling in cancer: research and clinical developments," OncoTargets and Therapy, vol. 6, pp. 1425-1435, 2013.

[34] E. V. Abel, E. J. Kim, J. Wu et al., "The Notch pathway is important in maintaining the cancer stem cell population in pancreatic cancer," PLoS ONE, vol. 9, no. 3, Article ID e91983, 2014.

[35] E. Lonardo, P. C. Hermann, M.-T. Mueller et al., "Nodal/activin signaling drives self-renewal and tumorigenicity of pancreatic cancer stem cells and provides a target for combined drug therapy," Cell Stem Cell, vol. 9, no. 5, pp. 433-446, 2011.

[36] C. Hage, V. Rausch, N. Giese et al., "The novel c-Met inhibitor cabozantinib overcomes gemcitabine resistance and stem cell signaling in pancreatic cancer," Cell Death \& Disease, vol. 4, article e627, 2013.

[37] M. Dillhoff, J. Liu, W. Frankel, C. Croce, and M. Bloomston, "MicroRNA-21 is overexpressed in pancreatic cancer and a potential predictor of survival," Journal of Gastrointestinal Surgery, vol. 12, no. 12, pp. 2171-2176, 2008.

[38] T. Moriyama, K. Ohuchida, K. Mizumoto et al., "MicroRNA21 modulates biological functions of pancreatic cancer cells including their proliferation, invasion, and chemoresistance," Molecular Cancer Therapeutics, vol. 8, no. 5, pp. 1067-1074, 2009.

[39] S. Liu, S. H. Patel, C. Ginestier et al., "MicroRNA93 regulates proliferation and differentiation of normal and malignant breast stem cells," PLoS Genetics, vol. 8, no. 6, Article ID e1002751, 2012.

[40] Y. Lu, J. Lu, X. Li et al., "MiR-200a inhibits epithelialmesenchymal transition of pancreatic cancer stem cell," $B M C$ Cancer, vol. 14, article 85, 2014.

[41] S. M. Sureban, R. May, S. A. Lightfoot et al., "DCAMKL-1 regulates epithelial-mesenchymal transition in human pancreatic cells through a miR-200a-dependent mechanism," Cancer Research, vol. 71, no. 6, pp. 2328-2338, 2011.

[42] U. Wellner, J. Schubert, U. C. Burk et al., "The EMT-activator ZEB1 promotes tumorigenicity by repressing stemness-inhibiting microRNAs," Nature Cell Biology, vol. 11, no. 12, pp. 14871495, 2009.

[43] Q. Ji, X. Hao, M. Zhang et al., "MicroRNA miR-34 inhibits human pancreatic cancer tumor-initiating cells," PLoS ONE, vol. 4, no. 8, Article ID e6816, 2009.

[44] M. Agostini and R. A. Knight, "miR-34: from bench to bedside," Oncotarget, vol. 5, no. 4, pp. 872-881, 2014.

[45] D. Pramanik, N. R. Campbell, C. Karikari et al., "Restitution of tumor suppressor microRNAs using a systemic nanovector inhibits pancreatic cancer growth in mice," Molecular Cancer Therapeutics, vol. 10, no. 8, pp. 1470-1480, 2011.

[46] S. Hasegawa, H. Eguchi, H. Nagano et al., "MicroRNA-1246 expression associated with CCNG2-mediated chemoresistance and stemness in pancreatic cancer," British Journal of Cancer, vol. 111, no. 8, pp. 1572-1580, 2014.

[47] E. V. Abel and D. M. Simeone, "Biology and clinical applications of pancreatic cancer stem cells," Gastroenterology, vol. 144, no. 6, pp. 1241-1248, 2013.

[48] P. Michieli, M. Mazzone, C. Basilico et al., “Targeting the tumor and its microenvironment by a dual-function decoy Met receptor," Cancer Cell, vol. 6, no. 1, pp. 61-73, 2004.

[49] M. Herreros-Villanueva, A. Zubia-Olascoaga, and L. Bujanda, "c-Met in pancreatic cancer stem cells: therapeutic implications," World Journal of Gastroenterology, vol. 18, no. 38, pp. 5321-5323, 2012. 
[50] D. Delitto, E. Vertes-George, S. J. Hughes, K. E. Behrns, and J. G. Trevino, "c-Met signaling in the development of tumorigenesis and chemoresistance: potential applications in pancreatic cancer," World Journal of Gastroenterology, vol. 20, no. 26, pp. 8458-8470, 2014.

[51] C. Li, J. Wu, M. Hynes et al., "c-Met is a marker of pancreatic cancer stem cells and therapeutic target," Gastroenterology, vol. 141, no. 6, pp. 2218.e5-2227.e5, 2011.

[52] M. P. Kim, J. B. Fleming, H. Wang et al., "ALDH activity selectively defines an enhanced tumor-initiating cell population relative to CD133 expression in human pancreatic adenocarcinoma," PLoS ONE, vol. 6, no. 6, Article ID e20636, 2011.

[53] C. Kahlert, F. Bergmann, J. Beck et al., "Low expression of aldehyde deyhdrogenase 1A1 (ALDH1A1) is a prognostic marker for poor survival in pancreatic cancer," BMC Cancer, vol. 11, article 275, 2011.

[54] H.-Q. Duong, J. S. Hwang, H. J. Kim, H. J. Kang, Y.-S. Seong, and I. Bae, "Aldehyde dehydrogenase $1 \mathrm{Al}$ confers intrinsic and acquired resistance to gemcitabine in human pancreatic adenocarcinoma MIA PaCa-2 cells," International Journal of Oncology, vol. 41, no. 3, pp. 855-861, 2012.

[55] M. L. O’Connor, D. Xiang, S. Shigdar et al., "Cancer stem cells: a contentious hypothesis now moving forward," Cancer Letters, vol. 344, no. 2, pp. 180-187, 2014.

[56] E. Proctor, M. Waghray, C. J. Lee et al., "Bmil enhances tumorigenicity and cancer stem cell function in pancreatic adenocarcinoma," PLoS ONE, vol. 8, no. 2, Article ID e55820, 2013.

[57] M. M. Cohen Jr., "The hedgehog signaling network," American Journal of Medical Genetics Part A, vol. 123, no. 1, pp. 5-28, 2003.

[58] K. Li, X.-X. Lv, F. Hua et al., "Targeting acute myeloid leukemia with a proapoptotic peptide conjugated to a toll-like receptor 2-mediated cell-penetrating peptide," International Journal of Cancer, vol. 134, no. 3, pp. 692-702, 2014.

[59] S.-N. Tang, J. Fu, D. Nall, M. Rodova, S. Shankar, and R. K. Srivastava, "Inhibition of sonic hedgehog pathway and pluripotency maintaining factors regulate human pancreatic cancer stem cell characteristics," International Journal of Cancer, vol. 131, no. 1, pp. 30-40, 2012.

[60] Y.-J. Chen, Y.-C. Huang, T.-H. Tsai, and H.-F. Liao, "Effect of wasabi component 6-(methylsulfinyl)hexyl isothiocyanate and derivatives on human pancreatic cancer cells," Evidence-Based Complementary and Alternative Medicine, vol. 2014, Article ID 494739, 6 pages, 2014.

[61] J.-B. Han, F. Sang, J.-J. Chang et al., "Arsenic trioxide inhibits viability of pancreatic cancer stem cells in culture and in a xenograft model via binding to SHH-Gli," OncoTargets and Therapy, vol. 6, pp. 1129-1138, 2013.

[62] M. Hebrok, "Hedgehog signaling in pancreas development," Mechanisms of Development, vol. 120, no. 1, pp. 45-57, 2003.

[63] M. Rodova, J. Fu, D. N. Watkins, R. K. Srivastava, and S. Shankar, "Sonic hedgehog signaling inhibition provides opportunities for targeted therapy by sulforaphane in regulating pancreatic cancer stem cell self-renewal," PLoS ONE, vol. 7, no. 9, Article ID e46083, 2012.

[64] Å. Apelqvist, H. Li, L. Sommer et al., "Notch signalling controls pancreatic cell differentiation," Nature, vol. 400, no. 6747, pp. 877-881, 1999.

[65] B. Bao, Z. Wang, S. Ali et al., "Notch-1 induces epithelialmesenchymal transition consistent with cancer stem cell phenotype in pancreatic cancer cells," Cancer Letters, vol. 307, no. 1, pp. 26-36, 2011.
[66] V. Stemmer, B. De Craene, G. Berx, and J. Behrens, "Snail promotes Wnt target gene expression and interacts with $\beta$ catenin," Oncogene, vol. 27, no. 37, pp. 5075-5080, 2008.

[67] S. Matsubara, Q. Ding, Y. Miyazaki, T. Kuwahata, K. Tsukasa, and S. Takao, "mTOR plays critical roles in pancreatic cancer stem cells through specific and stemness-related functions," Scientific Reports, vol. 3, article 3230, 2013.

[68] L. Sun, L. A. Mathews, S. M. Cabarcas et al., "Epigenetic regulation of SOX9 by the NF- $\kappa$ B signaling pathway in pancreatic cancer stem cells," STEM CELLS, vol. 31, no. 8, pp. 1454-1466, 2013.

[69] M. V. Iorio and C. M. Croce, "MicroRNA dysregulation in cancer: diagnostics, monitoring and therapeutics. A comprehensive review," EMBO Molecular Medicine, vol. 4, no. 3, pp. 143-159, 2012.

[70] Y. Lee, C. Ahn, J. Han et al., "The nuclear RNase III Drosha initiates microRNA processing," Nature, vol. 425, no. 6956, pp. 415-419, 2003.

[71] M. T. Bohnsack, K. Czaplinski, and D. Görlich, "Exportin 5 is a RanGTP-dependent dsRNA-binding protein that mediates nuclear export of pre-miRNAs," RNA, vol. 10, no. 2, pp. 185-191, 2004.

[72] R. Yi, Y. Qin, I. G. Macara, and B. R. Cullen, "Exportin5 mediates the nuclear export of pre-microRNAs and short hairpin RNAs," Genes \& Development, vol. 17, no. 24, pp. 30113016, 2003.

[73] E. Lund, S. Güttinger, A. Calado, J. E. Dahlberg, and U. Kutay, "Nuclear export of microRNA precursors," Science, vol. 303, no. 5654, pp. 95-98, 2004.

[74] R. F. Ketting, S. E. J. Fischer, E. Bernstein, T. Sijen, G. J. Hannon, and R. H. A. Plasterk, "Dicer functions in RNA interference and in synthesis of small RNA involved in developmental timing in C. elegans," Genes and Development, vol. 15, no. 20, pp. 26542659, 2001.

[75] E. Bernstein, S. Y. Kim, M. A. Carmell et al., "Dicer is essential for mouse development," Nature Genetics, vol. 35, no. 3, pp. 215$217,2003$.

[76] G. Hutvágner, J. McLachlan, A. E. Pasquinelli, É. Bálint, T. Tuschl, and P. D. Zamore, "A cellular function for the RNAinterference enzyme dicer in the maturation of the let-7 small temporal RNA," Science, vol. 293, no. 5531, pp. 834-838, 2001.

[77] S. W. Knight and B. L. Bass, "A role for the RNase III enzyme DCR-1 in RNA interference and germ line development in Caenorhabditis elegans," Science, vol. 293, no. 5538, pp. 22692271, 2001.

[78] K. Uchino, F. Takeshita, R.-U. Takahashi et al., "Therapeutic effects of microRNA-582-5p and $-3 p$ on the inhibition of bladder cancer progression," Molecular Therapy, vol. 21, no. 3, pp. 610-619, 2013.

[79] X. Yang, W. W. Du, H. Li et al., "Both mature miR-17-5p and passenger strand miR-17-3p target TIMP3 and induce prostate tumor growth and invasion," Nucleic Acids Research, vol. 41, no. 21, pp. 9688-9704, 2013.

[80] A. E. Pasquinelli, B. J. Reinhart, F. Slack et al., "Conservation of the sequence and temporal expression of let-7 heterochronic regulatory RNA," Nature, vol. 408, no. 6808, pp. 86-89, 2000.

[81] R. C. Lee, R. L. Feinbaum, and V. Ambros, "The C. elegans heterochronic gene lin- 4 encodes small RNAs with antisense complementarity to lin-14," Cell, vol. 75, no. 5, pp. 843-854, 1993.

[82] B. John, A. J. Enright, A. Aravin, T. Tuschl, C. Sander, and D. S. Marks, "Human microRNA targets," PLoS Biology, vol. 2, no. 11, article e363, 2004. 
83] R. C. Friedman, K. K.-H. Farh, C. B. Burge, and D. P. Bartel, "Most mammalian mRNAs are conserved targets of microRNAs," Genome Research, vol. 19, no. 1, pp. 92-105, 2009.

[84] U. A. Ørom, F. C. Nielsen, and A. H. Lund, "MicroRNA-10a binds the $5^{\prime}$ UTR of ribosomal protein mRNAs and enhances their translation," Molecular Cell, vol. 30, no. 4, pp. 460-471, 2008.

[85] P. Mandke, N. Wyatt, J. Fraser, B. Bates, S. J. Berberich, and M. P. Markey, "MicroRNA-34a modulates MDM4 expression via a target site in the open reading frame," PLoS ONE, vol. 7, no. 8, Article ID e42034, 2012.

[86] J. A. Leal and M. E. Lleonart, "MicroRNAs and cancer stem cells: therapeutic approaches and future perspectives," Cancer Letters, vol. 338, no. 1, pp. 174-183, 2013.

[87] P. Ceppi and M. E. Peter, "MicroRNAs regulate both epithelialto-mesenchymal transition and cancer stem cells," Oncogene, vol. 33, no. 3, pp. 269-278, 2014.

[88] L. Rosanò, F. Spinella, V. Di Castro et al., "Endothelin-1 promotes epithelial-to-mesenchymal transition in human ovarian cancer cells," Cancer Research, vol. 65, no. 24, pp. 11649-11657, 2005.

[89] Y. Shi, C. Liu, X. Liu, D. G. Tang, and J. Wang, "The microRNA miR-34a inhibits non-small cell lung cancer (NSCLC) growth and the CD44hi stem-like NSCLC cells," PLOS ONE, vol. 9, no. 3, Article ID e90022, 2014.

[90] B. Zhang, X. Pan, G. P. Cobb, and T. A. Anderson, "microRNAs as oncogenes and tumor suppressors," Developmental Biology, vol. 302, no. 1, pp. 1-12, 2007.

[91] N. Lynam-Lennon, S. G. Maher, and J. V. Reynolds, “The roles of microRNA in cancer and apoptosis," Biological Reviews, vol. 84, no. 1, pp. 55-71, 2009.

[92] O. A. Kent and J. T. Mendell, "A small piece in the cancer puzzle: microRNAs as tumor suppressors and oncogenes," Oncogene, vol. 25, no. 46, pp. 6188-6196, 2006.

[93] H.-X. Zhan, J.-W. Xu, D. Wu, T.-P. Zhang, and S.-Y. Hu, "Pancreatic cancer stem cells: new insight into a stubborn disease," Cancer Letters, vol. 357, no. 2, pp. 429-437, 2015.

[94] C. Ma, T. Huang, Y. C. Ding, W. Yu, Q. Wang, B. Meng et al., "MicroRNA-200c overexpression inhibits chemoresistance, invasion and colony formation of human pancreatic cancer stem cells," International Journal of Clinical and Experimental Pathology, vol. 8, no. 6, pp. 6533-6539, 2015.

[95] R. Albulescu, M. Neagu, L. Albulescu, and C. Tanase, “Tissular and soluble miRNAs for diagnostic and therapy improvement in digestive tract cancers," Expert Review of Molecular Diagnostics, vol. 11, no. 1, pp. 101-120, 2011.

[96] V. Haselmann, A. Kurz, U. Bertsch et al., "Nuclear death receptor TRAIL-R2 inhibits maturation of let-7 and promotes proliferation of pancreatic and other tumor cells," Gastroenterology, vol. 146, no. 1, pp. 278-290, 2014.

[97] E. Giovannetti, N. Funel, G. J. Peters et al., "MicroRNA-21 in pancreatic cancer: correlation with clinical outcome and pharmacologic aspects underlying its role in the modulation of gemcitabine activity," Cancer Research, vol. 70, no. 11, pp. 45284538, 2010.

[98] M. Garg, "MicroRNAs, stem cells and cancer stem cells," World Journal of Stem Cells, vol. 4, no. 7, pp. 62-70, 2012.

[99] A. Navarro and M. Monzó, "MicroRNAs in human embryonic and cancer stem cells," Yonsei Medical Journal, vol. 51, no. 5, pp. 622-632, 2010.
[100] A. Ahmed, C. Specht, and M. R. Lowden, "A patient with confusion and dizziness," Journal of Clinical Neuroscience, vol. 19, no. 9, p. 1281, 2012.

[101] D. E. Jung, J. Wen, T. Oh, and S. Y. Song, "Differentially expressed microRNAs in pancreatic cancer stem cells," Pancreas, vol. 40, no. 8, pp. 1180-1187, 2011.

[102] B. Bao, Z. Wang, S. Ali et al., "Metformin inhibits cell proliferation, migration and invasion by attenuating CSC function mediated by deregulating miRNAs in pancreatic cancer cells," Cancer Prevention Research, vol. 5, no. 3, pp. 355-364, 2012. 

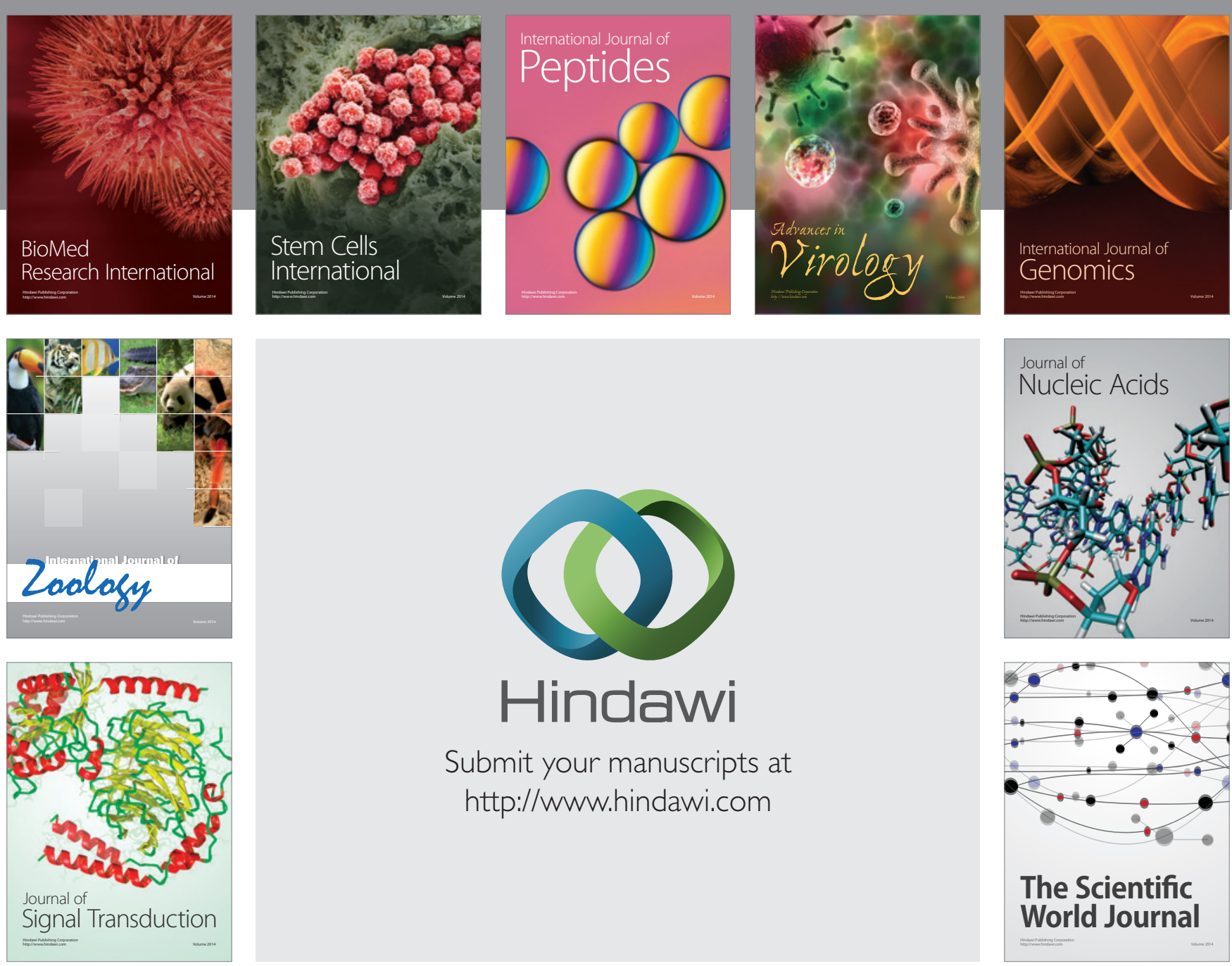

Submit your manuscripts at

http://www.hindawi.com
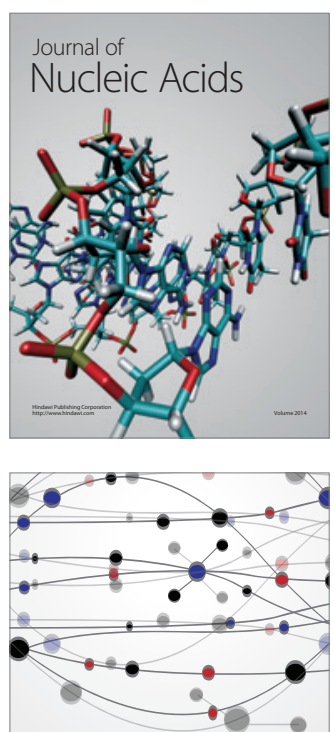

The Scientific World Journal
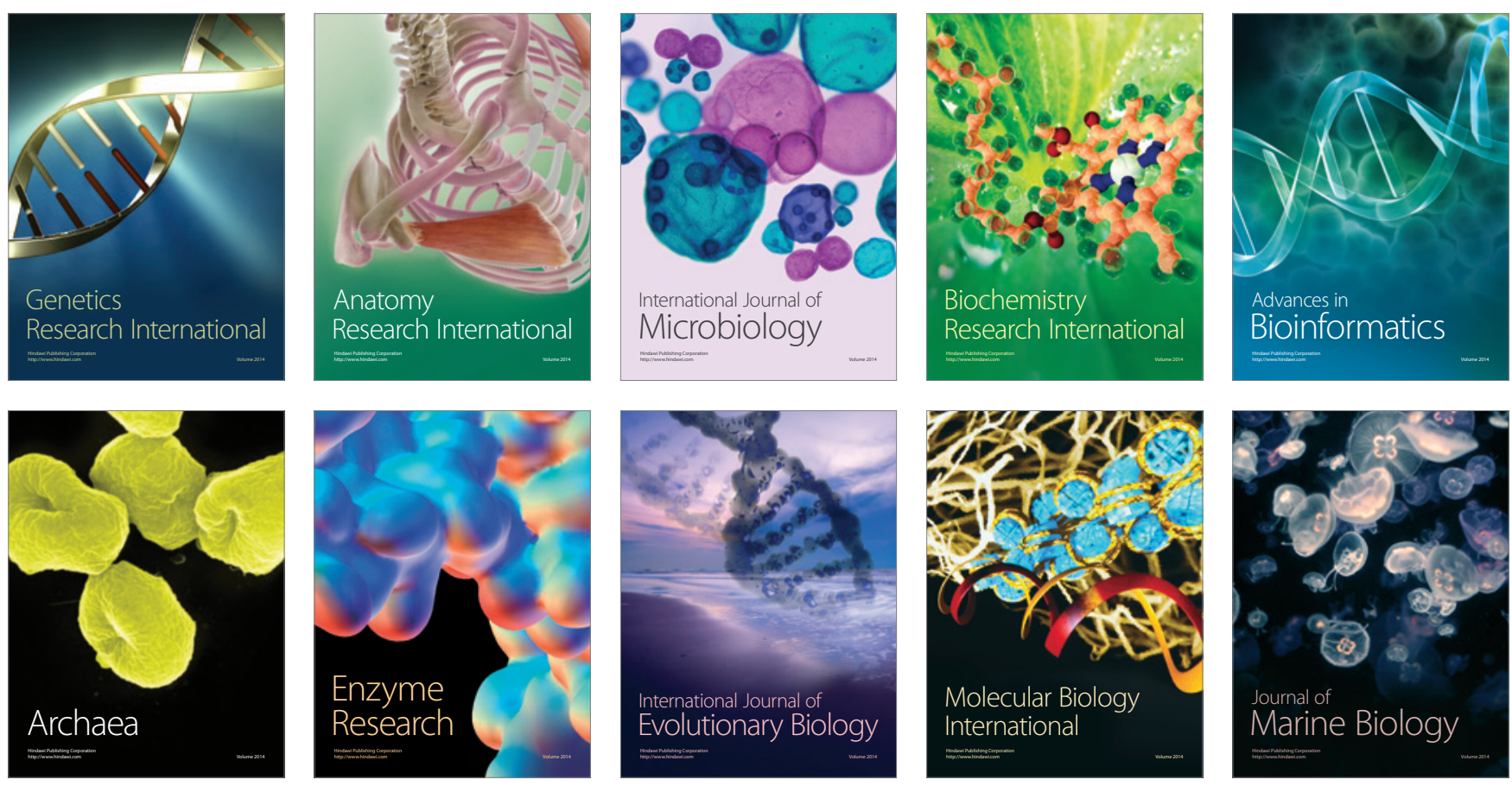